Original Article

\title{
Changes in the spinal curvature, degree of pain, balance ability, and gait ability according to pregnancy period in pregnant and nonpregnant women
}

\author{
Hyunju Yoo, MS, PT ${ }^{1)}$, Doochul Shin, MS, PT ${ }^{1)}$, Changho Song, PhD, $\mathrm{PT}^{1)^{*}}$ \\ 1) Department of Physical Therapy, College of Health and Welfare, Sahmyook University: 815 \\ Hwarang-ro, Nowon-gu, Seoul 139-742, Republic of Korea
}

\begin{abstract}
Purpose] The aim of this study was to investigate the changes in pain intensity, spinal curvature, and balance and gait ability according to the pregnancy period. [Subjects] Nineteen pregnant women and fifteen nonpregnant women were recruited in this study. [Methods] The pain intensity, spinal curvature, gait, and balance of pregnant women were measured according to the pregnant period (2nd and 3rd trimester). The changes in the pregnant women were also compared with those in the nonpregnant women. [Results] The pain intensity and spinal curvature in the third trimester of pregnancy were significantly increased compared with the second trimester. Only the lumbar spine curvature in the third trimester pregnancy was significantly greater in the pregnant women than in non-pregnant women. The gait velocity and cadence in the third trimester of pregnancy showed a significant decrease compared with the second trimester. The gait speed in the second and third trimester of pregnancy showed a significant decrease in the pregnant women compared with nonpregnant women. Balance in the third trimester of pregnancy showed significant improvement compared with the second trimester. The balance of the pregnant women showed a significant decrease compare with that nonpregnant women only on unstable surfaces. [Conclusion] These research findings can be used as basic data for health promotion programs for sound daily activities in pregnant women.

Key words: Pregnant women, Spinal curvatures, Gait
\end{abstract}

(This article was submitted Jun. 30, 2014, and was accepted Aug. 24, 2014)

\section{INTRODUCTION}

As a fetus grows, a variety of changes appear in a pregnant woman's body. The thoracic and lumbar spine curvature change ${ }^{1)}$, pain in the low back and pelvic region can increase $^{2)}$, and the balance and gait pattern also change ${ }^{3-5)}$. Previous studies reported that the center of gravity of pregnant women moves towards the abdomen, resulting in an increase in lumbar lordosis, posterior tilt of the sacrum and movement of the head to the back to compensate for the increased weight as the fetus grows ${ }^{6-8)}$. Pregnancy-related low back pain (PR-LBP) is a common symptom during pregnancy $(50.9 \%)^{9,10)}$, and $49 \%$ of pregnant women complain of pelvic region pain lasting more than three months, $10 \%$ of pregnant women complain of pelvic region pain throughout pregnancy $^{2}$. In the year after birth, $72 \%$ of the women experience lumbo-pelvic region pain ${ }^{11)}$, and some complain of

*Corresponding author. Changho Song (E-mail: chsong@syu. ac.kr)

(C2015 The Society of Physical Therapy Science. Published by IPEC Inc. This is an open-access article distributed under the terms of the Creative Commons Attribution Non-Commercial No Derivatives (by-ncnd) License $<$ http://creativecommons.org/licenses/by-nc-nd/3.0/>. continuous pain in the low back and pelvic region for up to 3 years after birth ${ }^{12)}$.

Weeks $1-12,13-28$, and $29-40$ of the pregnancy period are generally classified as the first, second, and third trimesters, respectively ${ }^{13)}$, and PR-LBP normally increases in intensity during pregnancy ${ }^{14)}$, reaching a peak in both prevalence and severity in the third trimester ${ }^{15,16)}$. PR-LBP in the third trimester has been found to be associated with disability and a reduced quality of life during pregnancy ${ }^{17}$ ) as well as postpartum depression ${ }^{18)}$.

Regarding the changes in gait characteristics of pregnant women, Foti et al. ${ }^{19)}$ reported no significant differences between pregnant and nonpregnant women in terms of walking velocity, stride length, or stride frequency during level walking. On the other hand, $\mathrm{Wu}$ et al. ${ }^{20)}$ reported that the comfortable walking velocity in pregnant women was reduced, and Bird et al. ${ }^{21)}$ found that step width when walking increased throughout pregnancy. Several studies reported the temporal-spatial characteristics of gait in late pregnancy ${ }^{7,20,22)}$, but the results were ambiguous.

The forward-shifted center of gravity of pregnant women affects balance, increasing the amount and speed of postural sway $^{23}$. In addition, $27 \%$ of pregnant women have a risk of falling down ${ }^{24)}$. When a fall occurs, it might cause an emergency situation in $40 \%$ of pregnant women, such as head 
injury, fracture, or miscarriage ${ }^{25}$. Education of pregnant women concerning pain relief and correct methods of movement is needed because various physical and functional changes due to pregnancy might cause mental problems in pregnant women ${ }^{26)}$. Therefore, the physical and functional changes depending on the pregnancy period need to be understood.

However, few cohort studies on the changes in pain, spinal curvature, balance, and gait ability according to the pregnancy period have been reported. So the present study examined the differences in pain intensity, spinal curvature, and gait and balance ability between pregnant and nonpregnant women during the pregnancy period with the aim of proving basic data for health care in pregnant women

\section{SUBJECTS AND METHODS}

Thirty-four participants, 19 pregnant (age, $29.54 \pm$ 3.45 years; height, $162.18 \pm 3.60 \mathrm{~cm}$; weight, $58.15 \pm 6.58$ $\mathrm{kg}$; Pregnancy duration, $26 \pm 1.67$ weeks) and 15 nonpregnant (age, $28.85 \pm 3.02$ years; height, $161.6 \pm 4.21 \mathrm{~cm}$, weight, $53.11 \pm 5.29 \mathrm{~kg}$ ) women, were enrolled in this study. Participants were excluded for the following reasons: if they had problems maintaining a standing posture or walking; surgery of the lumbar spine, pelvis, hip, or knee; fractures, tumors, or active inflammation in the lumbar spine or pelvis; Bechterew's syndrome, Scheuermann's syndrome, active polyarthritis, rheumatoid arthritis, or severe osteoporosis; or pulmonary, cardiac, visual, auditive, or cognitive disorders $^{20)}$. The participants were informed of the aim and process of this research and were asked to sign a consent form regarding the possible risk and discomfort that might result from the investigations. The protocol was approved by the institutional Review Board and Ethics committee of SahmYook University.

This was a single-blinded cross-sectional study examining characteristics of the spine curvature (thorax, lumbar), the temporal-spatial gait parameters (gait velocity, cadence), the static balance parameters (weight distribution index), and a pain scale in the second and third trimesters in pregnant women and nonpregnant women. Before the measurements, the participants were informed about the process. Nineteen pregnant women in the second trimester participated in the measurements. Three pregnant women left the study due to dizziness or refusal to participate, so 16 pregnant women in the third trimester ultimately participated in the measurements. Fifteen nonpregnant women were also subjected to the same measurements as the pregnant women, except for pain, and were compared with the pregnant women (Fig. 1).

BackMapper (ABW GmbH, Frickenhausen, Germany), which is a three-dimensional spinal diagnostic imaging system, was used to measure the angle of the thoracic and lumbar spine curvature for those pregnant women who were vulnerable to radiation and mediation. BackMapper is an apparatus that measures precisely the spinal form, location, and degree of distortion, as if looking at the spinal form from the backward, forward, downward, and upward directions with two cameras. The 3-axis accelerometer data obtained with this apparatus is converted in to an image. This apparatus can analyze the distribution of body muscles as well as the loca-

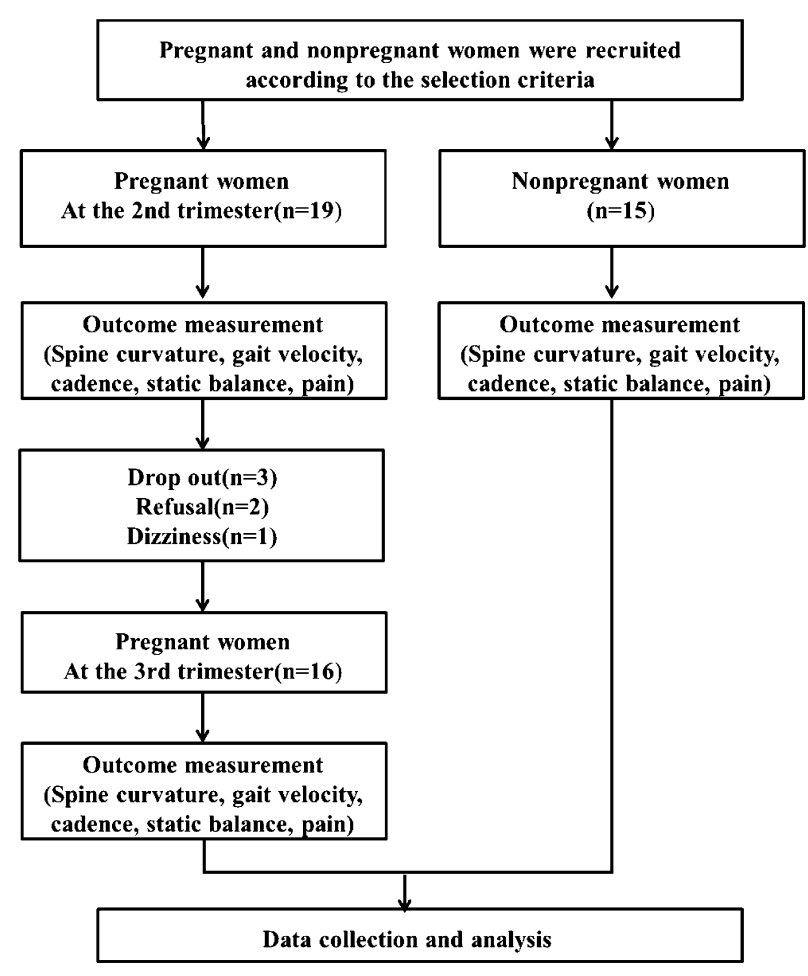

Fig. 1. Flow chart of the present study

tion of the skeleton using a range of variables. After dressing in a closed locker room, the participants stood just behind a line placed in front of the cameras 2 meters away, with their heels side by side, knee extended, and eyes looking straight ahead. The posture should be measured in a natural steady state, with no strain on the body, so the participants needed to pose themselves in a natural standing posture. The markers were attached to the 7 th cervical spinous process, inferior angle of the scapulae, the 5th lumbar transverse process, and the 1st sacral spinous process for precise measurements. The angle of the thoracic curvature was measured by connecting a vertical line and tangent line between the 7th cervical spinous process and 6th thoracic spinous process. The angle of the lumbar curvature was measured by connecting a vertical line and tangent line between the 5th lumbar spinous process and the 2nd lumbar spinous process. Measurements were repeated 3 times, and the mean was used.

A GAITRite system was used to assess the temporalspatial characteristics of gait. A walkway with an active measurement area of $61 \mathrm{~cm} \times 5 \mathrm{~m}$ fitted with 16,128 pressure sensors was used. The sensors were arranged in a grid pattern with each placed $1.27 \mathrm{~cm}$ on center. This system provides quantitative information about gait. The data were analyzed using the GAITRite GOLD, Version 3.2b, software (CIR System Inc., Sparta, NJ, USA, 2007), which provided the mean temporal and spatial parameters. The procedure used was as follows: A GAITRite mat was positioned in a gymnasium to allow the subjects to walk $2 \mathrm{~m}$ before reaching and after leaving the mat at a self-selected comfortable speed. Temporal measurements, i.e., the gait velocity and cadence, and spatial measurements, i.e., step length, stride length, and single limb support percentage, were determined 
by computer analysis. Only the temporal gait parameters (gait velocity and cadence) were measured. Measuremenst were repeated 3 times, and the mean value was used for further analysis.

Static posturography was conducted using a Tetrax ${ }^{\circledR}$ system (Sunlight Medical Ltd., at Ram Gan, Israel). The force plate of the Tetrax ${ }^{\circledR}$ system was formed with four separate plates. Each force plate measures the perpendicular pressure of the anterior and posterior feet. The force plates for the anterior feet (left force plate, B; right force plate, D) are rectangles $12 \times 19 \mathrm{~cm}$ in size, and the force plates for the posterior feet (left force plate, A; right force plate, C) are squares $12 \times 12 \mathrm{~cm}$ in size. The data obtained from the pressure burden of each force plate when the subject stood on them was amplified and filtered, passed to a computer, and analyzed using the Tetrax ${ }^{\circledR}$ software program. Posturography recorded the movement direction of the weight using the movement pattern of the center of pressure measured by the pressure sensors of the apparatus. The weight distribution index (WDI) reflects the level of weight distributed on the four force plates, with the normal index being 4 to 6 . The normal percentage of weight placed on each of the four force plates was $25 \%$. A higher percentage than the $25 \%$ indicates a pathologic state in which the weight distribution has changed radically ${ }^{27}$. In this study, the WDI was calculated by measuring the anterior-posterior and mediallateral changes in weight when the eyes were opened and closed while standing on a normal plate and flexible plate. Measurements were performed for every 30 seconds while standing comfortably and repeated 3 times. The mean value was used for further analysis.

The visual analogue scale (VAS) is the most widely used method for evaluating the degree of pain with high sensitivity. The VAS is represented as a $10 \mathrm{~cm}$ horizontal line devided into $1-\mathrm{cm}$ section of the horizontal line represent 1 point, giving a score for each question of the VAS of 0 to 10 points. The location marked on the horizontal line by a subject represents the degree of pain. The reliability for evaluating the degree of pain ranges from 0.76 to 0.84 . In this study, the VAS was used to measure the degree of pain for the low back, pelvis, knee, calf, foot, shoulder, and hand each region of the pregnant women.

Statistical analysis was carried out using the SPSS Statistical Package, version 19.0 (SPSS Inc, Chicago, IL, USA). All values are expressed as means and standard deviations. Repeated measures analysis of variance (ANOVA) was used to compare the changes between the middle and late periods of pregnancy. One-way ANOVA was used to compare the changes among pairs of trimesters in the pregnant and nonpregnant women. A Bonferroni test was used as a post test. Statistical significance was set as $\mathrm{p}<0.05$ for all procedures.

\section{RESULTS}

The scores for the VAS in the third trimester of pregnancy increased significantly compared with those in the second trimester for the low back, pelvic, calf, foot, and shoulder. Also, pain was felt in two regions, the knee (0.72) and hand (1.00), in the third trimester of pregnancy (Table 1).

The thoracic spine curvature between the second $\left(10.67^{\circ}\right)$
Table 1. Changes in pain

\begin{tabular}{lcc}
\hline & $\begin{array}{c}\text { Pregnant women } \\
\text { in the second } \\
\text { trimester }(\mathrm{n}=16)\end{array}$ & $\begin{array}{c}\text { Pregnant women } \\
\text { in the third } \\
\text { trimester }(\mathrm{n}=16)\end{array}$ \\
\hline Low back (score) & $4.2 \pm 3.5$ & $4.8 \pm 3.7^{*}$ \\
Pelvis (score) & $5.8 \pm 3.1$ & $7.3 \pm 1.8^{*}$ \\
Knee (score) & 0.0 & $0.7 \pm 0.5^{*}$ \\
Calf (score) & $1.6 \pm 0.7$ & $2.4 \pm 1.1^{*}$ \\
Foot (score) & $0.3 \pm 0.3$ & $1.2 \pm 0.7^{*}$ \\
Shoulder (score) & $1.6 \pm 0.7$ & $3.6 \pm 1.0^{*}$ \\
Hand (score) & 0.0 & $1.0 \pm 0.7^{*}$ \\
\hline
\end{tabular}

Outcome data: mean \pm SD

* Significant difference between the second and third trimesters

and third trimesters $\left(11.50^{\circ}\right)$ showed a significant difference $(\mathrm{p}<0.01)$. The lumbar spine curvature between the second trimester $\left(8.96^{\circ}\right)$ and third trimester $\left(9.98^{\circ}\right)$ showed a significant difference $(\mathrm{p}<0.05)$. There was no significant difference in the thoracic spine curvature between the pregnant and nonpregnant women. There was significant difference $(\mathrm{p}<0.05)$ in the lumbar spine curvature between the pregnant women in the third trimester $\left(9.98^{\circ}\right)$ and the nonpregnant women $\left(7.27^{\circ}\right)$ (Table 2$)$.

There was a significant difference $(\mathrm{p}<0.05)$ in the gait velocity between the second trimester $(113.19 \mathrm{~cm} / \mathrm{s})$ and third trimester $(102.00 \mathrm{~cm} / \mathrm{s})$. The gait velocity of the nonpregnant women was $125.35 \mathrm{~cm} / \mathrm{s}$, and there was significant difference $(\mathrm{p}<0.05)$ between the pregnant women in the second trimester and the nonpregnant women and between the pregnant women in the third trimester and the nonpregnant women. There was also significant difference $(\mathrm{p}<0.05)$ in the cadence between the second trimester (108.68 steps/ $\mathrm{min}$ ) and third trimester ( $98 \mathrm{steps} / \mathrm{min})$. The cadence of the nonpregnant women was $113.76 \mathrm{steps} / \mathrm{min}$, and there was significant difference $(\mathrm{p}<0.05)$ between the pregnant women in the second trimester and the nonpregnant women and between the pregnant women in the third trimester and the nonpregnant women (Table 3).

The scores of the WDI under the conditions of standing on a normal plate with the eyes open in the pregnant women showed a significant difference between the second trimester $(5.60)$ and the third trimester $(4.25)(p<0.05)$. The scores of the WDI under the conditions of standing on the normal plate with the eyes closed in the pregnant women showed a significant difference between the second trimester (5.68) and the third trimester (4.29) $(\mathrm{p}<0.05)$. The scores of the WDI under the conditions of standing on a flexible plate with the eyes opened in the pregnant women showed a significant difference between the second trimester (8.90) and the third trimester (7.32) $(\mathrm{p}<0.05)$. The scores of the WDI under the conditions of standing on a flexible plate with the eyes closed in the pregnant women showed a significant difference between the second trimester (10.24) and the third trimester (8.06) $(\mathrm{p}<0.05)$. WDI score for nonpregnant women were 3.85 and 4.27 under the conditions of standing on the normal plate with the eyes open and closed, respectively, and were 5.65 and 5.30 under the conditions of standing on the flex- 
Table 2. Changes in the spine curvature

\begin{tabular}{lccc}
\hline & $\begin{array}{c}\text { Pregnant women in } \\
\text { the second trimester } \\
(\mathrm{n}=16)\end{array}$ & $\begin{array}{c}\text { Pregnant women in } \\
\text { the third trimester } \\
(\mathrm{n}=16)\end{array}$ & $\begin{array}{c}\text { Nonpregnant women } \\
(\mathrm{n}=15)\end{array}$ \\
\hline Thoracic curvature $\left(^{\circ}\right)$ & $10.7 \pm 2.1$ & $11.5 \pm 2.4^{*}$ & $10.6 \pm 2.9$ \\
Lumbar curvature $\left(^{\circ}\right)$ & $9.0 \pm 1.7$ & $1.0 \pm 1.9^{*}$ & $7.3 \pm 1.3^{3}$ \\
\hline Outcome data: mean \pm SD \\
* Significant difference between the second and third trimesters \\
3 Significant difference only with the third trimester
\end{tabular}

Table 3. Changes in gait ability

\begin{tabular}{lccc}
\hline & $\begin{array}{c}\text { Pregnant women in } \\
\text { the second trimester } \\
(\mathrm{n}=16)\end{array}$ & $\begin{array}{c}\text { Pregnant women in } \\
\text { the third trimester } \\
(\mathrm{n}=16)\end{array}$ & $\begin{array}{c}\text { Nonpregnant women } \\
(\mathrm{n}=15)\end{array}$ \\
\hline Speed $(\mathrm{cm} / \mathrm{s})$ & $113.2 \pm 7.7$ & $102.0 \pm 8.4^{*}$ & $125.4 \pm 13.9^{2,3}$ \\
Cadence $(\mathrm{steps} / \mathrm{min})$ & $108.7 \pm 5.0$ & $98.0 \pm 7.9^{*}$ & $113.8 \pm 6.2^{2,3}$ \\
\hline
\end{tabular}

Outcome data: mean \pm SD

* Significant difference between the second and third trimesters

${ }^{2,3}$ Significant difference with the second and third trimesters

Table 4. Changes in the balance ability

\begin{tabular}{lccc}
\hline & $\begin{array}{c}\text { Pregnant women in } \\
\text { the second trimester } \\
(\mathrm{n}=16)\end{array}$ & $\begin{array}{c}\text { Pregnant women in } \\
\text { the third trimester } \\
(\mathrm{n}=16)\end{array}$ & $\begin{array}{c}\text { Nonpregnant women } \\
(\mathrm{n}=15)\end{array}$ \\
\hline NO (score) & $5.6 \pm 3.3$ & $4.3 \pm 2.2^{*}$ & $3.9 \pm 1.2$ \\
$\mathrm{NC}$ (score) & $5.7 \pm 2.9$ & $4.3 \pm 2.1^{*}$ & $4.3 \pm 1.6$ \\
FO (score) & $8.9 \pm 4.0$ & $7.3 \pm 3.1^{*}$ & $5.7 \pm 3.6^{2,3}$ \\
FC (score) & $10.2 \pm 4.6$ & $8.1 \pm 3.0^{*}$ & $5.3 \pm 1.8^{2,3}$ \\
\hline Outcome data: mean \pm SD & \\
NO: Normal plate, eye open; NC: Normal plate, eye closed; FO: Flexible plate, eye open; FC: \\
Flexible plate, eye closed \\
* Significant difference between the second and third trimesters \\
2,3 Significant difference with the second and third trimesters
\end{tabular}

ible plate with the eyes open and closed, respectively. In a comparison of the WDI scores of the pregnant women and nonpregnant women, there were no significant differences in the second and third trimesters of pregnancy regardless of whether the eyes were open or closed while standing on a stable surface, but the scores increased significantly in the pregnant women in third trimesters of pregnancy while standing on an unstable surface compared with the nonpregnant women $(\mathrm{p}<0.05)$ (Table 4).

\section{DISCUSSION}

This study examined the characteristics of the pain intensity for each region, spinal curvature, gait and balance ability according to the second and third trimesters of pregnancy in pregnant women with the aim of proving basic data for pregnant women. The degree of pain of the pregnant women in the pelvic region, low back, shoulder, calf, and foot according to pregnancy period was evaluated using a VAS. As a result, the pain was found to increase significantly in all regions from the second trimester to the third trimester of pregnancy. The degree of pain according to region in the second trimester of pregnancy was in the order of the pelvic area (5.81), low back (4.18), calf (1.63), and shoulder (1.63), foot $(0.27)$, knee $(0)$, and hands $(0)$. In the third trimester, the degree of pain was in the order of the knee (8), pelvic area (7.32), low back (4.81), shoulder (3.55), calf (2.36), foot (1.18), and hands (1).

During pregnancy, secretion of the hormone relaxin increases more than 10-fold. This hormone relaxes the peripheral and sacroiliac joint, which causes instability and dysfunction of the hand and pelvic region ${ }^{2}, 28,29$ ). In addition, the load on the knee extension muscles of pregnant women is approximately 1.2 times that of nonpregnant women ${ }^{30)}$. Secretion of relaxin and the increased loading on knee extension muscles may cause knee and hand pain in pregnant women in the third trimester. In addition, the spinal curvature according to the growth of the fetus and the increase in weight load applied to the joints due to the change in the center of gravity may increase the pain in the lumbo-pelvic region ${ }^{6}$. Sihvonen et al. ${ }^{31)}$ reported that low back pain in pregnant women begins in the 18th week of 
pregnancy, reaching a maximum between 24 and 36 weeks. Berg et al. ${ }^{2)}$ reported that the highest level of pain in the low back and pelvic region appeared between 26 and 35 weeks of pregnancy. As with their research findings, the present study found that the pain in the low back and pelvic region in pregnant women was significantly higher in the third trimester of pregnancy compared with the second trimester of pregnancy.

This study measured the curvature of the thoracic and lumbar spine using BackMapper in pregnant women. As a result, the angles of the thoracic and lumbar spine curvature increased by $0.83^{\circ}$ and $1.02^{\circ}$, respectively, in the third trimester of pregnancy compared with the second trimester. The angle of the lumbar spine curvature increased significantly $\left(2.71^{\circ}\right)$ in the third trimester in the pregnant women compared with nonpregnant women.

This indicates that changes in the spinal curvature due to pregnancy occurred intensively in the third trimester, and the low back pain of pregnant women in the first and second trimesters might not be the result of these changes in spinal curvature. These results were similar to those in previous studies. Franklin et al. ${ }^{7)}$ compared the posture of women in the first and second trimesters and reported that the angle of the lumbar spine curvature increased by $5.9^{\circ}$, the anterior tilt of the pelvis increased by $4^{\circ}$, and the position of the head moved to the posterior. By comparing with previous studies, it could be seen that even though the changes in degree were not much, there was tendency to increase.

Gilleard et al. ${ }^{32)}$, who compared the changes in the sitting and standing postures of pregnant women, reported that lumbar spine lordosis increased in pregnant women compared with nonpregnant women. In another study, the spinal curvature of pregnant women was measured with Formatri$\mathrm{cII}^{6)}$. As a result, the angle of the thoracic spine curvature increased by $12 \%$ between 12 and 22 weeks and increased by a total of $24 \%$ between 12 and 32 weeks. The lumbar spine curvature increased by $18 \%$ between 12 and 22 weeks and by a total of $41 \%$ between 12 and 32 weeks. Therefore, the spinal curvature of pregnant women increases toward the end of pregnancy. Regarding the changes in spinal curvature due to pregnancy, possible causes include increased weight distribution to the breast and stomach as well as the flexible ligaments and soft tissues. As the weight distribution increases in the anterior part of body, the center of gravity changes, which causes changes in posture. In particular, the lordosis of the neck and lumbar spine is increased, the shoulder girdle becomes posteriorly dislocated, and hyperextension of the knee occurs. These could be the representative features for correcting the altered center of gravity and widening the base of support due to pregnancy ${ }^{33)}$. Knee pain which showed the greatest change in the third trimester compared with the second trimester in the present study, is believed to be associated with the changes in the weight distribution and hyperextension of the knee joint due to the increase in lumbar lordosis in the third trimester.

This study found that the gait speeds of the pregnant women were $113.19 \mathrm{~cm} / \mathrm{s}$ in the second trimester and $102.00 \mathrm{~cm} / \mathrm{s}$ in the third trimester, which were $12.16 \mathrm{~cm} / \mathrm{s}$ and $23.35 \mathrm{~cm} / \mathrm{s}$ less, respectively, than those of the nonpregnant women $(125.35 \mathrm{~cm} / \mathrm{s})(\mathrm{p}<0.05)$. The cadences of the pregnant women in the second and third trimesters were $108.68 \mathrm{steps} / \mathrm{min}$ and $98 \mathrm{steps} / \mathrm{min}$, respectively, showing a significant difference $(\mathrm{p}<0.05)$. In contrast, the cadence of nonpregnant women was significantly higher (113.76 steps/ $\min )(p<0.05)$. Several studies reported that the reduction in gait speed in pregnant women was associated with unilateral pelvic pain ${ }^{2)}$ or the combination of careful movement to minimize falling and an inability to see the surface directly beneath them, as that area is blocked by their abdomen ${ }^{13)}$. Moreover, if the pelvic anterior tilt and lumbar lordosis increased, the center of gravity would be located at the back of the hip joints, anterior to knee and ankle joint, resulting in hyper-extension of the knee joint. A hyperextended knee joint in a pregnant women in the third trimester causes weakness of the knee joint flexors and hip joint extensors ${ }^{34)}$. The weakness of those muscles might decreased gait speed ${ }^{35)}$. On the other hand, the research findings regarding the gait speed of pregnant women were the same as those reported by $\mathrm{Wu}$ et al. ${ }^{36)}$ and Byrne et al. ${ }^{37)}$ but different from those reported by Branco et al. ${ }^{13)}$ and Gilleard ${ }^{38)}$. Therefore, the gait speed of pregnant women cannot be defined accurately yet due to the differences in the results for pregnant women depending on the period of pregnancy. Accordingly, more study of the factors related to the gait speed of pregnant women will be needed.

In this study, the changes in the WDI measured using the Tetrax system were 5.60 points in the second trimester in pregnant women with their eyes open (NO) while standing on the stable surface and 4.25 points in the third trimester in pregnancy women $(\mathrm{p}<0.05)$. With their eyes closed $(\mathrm{NC})$ while standing on the stable surface, the changes in the WDI were 5.68 and 4.29 points in the second and third trimesters, respectively, showing a significant decrease $(p<0.05)$. On the unstable surface with their eyes open, the changes in the WDI in the second and third trimester in pregnancy women were 8.90 and 7.32 points, respectively, showing a significant decrease $(\mathrm{p}<0.01)$. With their eyes closed, the changes in the WDI in the second and third trimester in pregnancy women were 10.24 and 8.06 points, respectively, showing the most significant decrease $(2.18 ; \mathrm{p}<0.01)$. These findings show that the balance of pregnant women increases toward the third trimester of pregnancy due to a decrease in the weight distribution index. In a comparison of the WDI between the pregnant women and nonpregnant women, there were no significant differences in the second and third trimesters of pregnancy regardless of whether the eyes were open or closed while standing on a stable surface, but the WDI increased significantly in the pregnant women in second and third trimesters of pregnancy on an unstable surface compared with that in the nonpregnant women. Based on the above information, this means that the balance of pregnant women in the third trimester is better than that in the second trimester but similar to that nonpregnant women. Nevertheless, on an unstable surface, the balance of pregnant women appeared to deteriorate in the second and third trimesters compared with that of the nonpregnant women. These results suggest that pregnant women should take care to prevent falling down when walking on an unstable surface beginning in the second trimester of pregnancy and should be more careful in the second trimester than in the third trimester of 
pregnancy. According to previous studies comparing the balance of pregnant women, when comparing women who had experienced falling down with women who had not, and the back and forth body sway with the sway velocity for the degree of stimulation in ordinary women, it was found that the body sway of pregnant women who had experienced falling down was smaller than that of pregnant women who had not experienced falling down, and their sway velocity was significantly slower $(p<0.001)$. On the other hand, there were no differences between pregnant women without a falling down experience and ordinary women ${ }^{23}$. This shows that pregnant women who had experienced falling down respond slowly to external stimuli and have less dynamic stability.

This study did not measure the dynamic changes in the pelvis and limbs, changes in spinal curvature that may cause changes in gait, or changes accompanied pelvic tilt. In addition, when shoulder pain increases significantly, the position changes of the shoulder girdle and upper limb need to be measured. Women in early pregnancy (weeks 1-16) were not subjected to measurement in this study, and changes before and after birth were not compared. A future study will examine more subjects and compare the difference between early pregnancy and after childbirth, shoulder girdle position, and changes in pelvic tilt. This study examined the characteristics of pain, spine curvature, and gait and balance ability in the second and third trimesters of pregnancy and compared with those of nonpregnant women.

The findings of this study can be used as basic data for health promotion programs for sound daily activities in pregnant women.

\section{REFERENCES}

1) Hirabayashi $Y$, Shimizu R, Saitoh $K$, et al.: Anatomical configuration of the spinal column in the supine position. I. A study using magnetic resonance imaging. Br J Anaesth, 1995, 75: 3-5. [Medline] [CrossRef]

2) Berg G, Hammar M, Möller-Nielsen J, et al.: Low back pain during pregnancy. Obstet Gynecol, 1988, 71: 71-75. [Medline]

3) Katonis P, Kampouroglou A, Aggelopoulos A, et al.: Pregnancy-related low back pain. Hippokratia, 2011, 15: 205-210. [Medline]

4) Suputtitada A, Wacharapreechanont $T$, Chaisayan P: Effect of the "sitting pelvic tilt exercise" during the third trimester in primigravidas on back pain. Journal of the Medical Association of Thailand = Chotmaihet thangphaet, 2002, 85 Suppl 1: S170-179.

5) Yu Y, Chung HC, Hemingway L, et al.: Standing body sway in women with and without morning sickness in pregnancy. Gait Posture, 2013, 37: 103-107. [Medline] [CrossRef]

6) Yousef AM, Hanfy HM, Elshamy FF, et al.: Postural changes during normal pregnancy. J Am Sci, 2011, 7: 1013-1018.

7) Franklin ME, Conner-Kerr T: An analysis of posture and back pain in the first and third trimesters of pregnancy. J Orthop Sports Phys Ther, 1998, 28: 133-138. [Medline] [CrossRef]

8) Hirabayashi Y, Shimizu R, Fukuda H, et al.: Anatomical configuration of the spinal column in the supine position. II. Comparison of pregnant and non-pregnant women. Br J Anaesth, 1995, 75: 6-8. [Medline] [CrossRef]

9) Wang SM, Dezinno P, Maranets I, et al.: Low back pain during pregnancy: prevalence, risk factors, and outcomes. Obstet Gynecol, 2004, 104: 65-70. [Medline] [CrossRef]

10) Chang HY, Jensen MP, Yang YL, et al.: Risk factors of pregnancy-related lumbopelvic pain: a biopsychosocial approach. J Clin Nurs, 2012, 21: 1274-1283. [Medline] [CrossRef]

11) Padua L, Caliandro P, Aprile I, et al.: Back pain in pregnancy: 1-year follow-up of untreated cases. Eur Spine J, 2005, 14: 151-154. [Medline] [CrossRef]

12) Norén $L$, Ostgaard $S$, Johansson $G$, et al.: Lumbar back and posterior pelvic pain during pregnancy: a 3-year follow-up. Eur Spine J, 2002, 11: 267-271. [Medline] [CrossRef]
13) Branco M, Santos-Rocha R, Aguiar L, et al.: Kinematic analysis of gait in the second and third trimesters of pregnancy. J Pregnancy, 2013, 2013: 718095. [Medline] [CrossRef]

14) Kristiansson P, Svärdsudd K, von Schoultz B: Back pain during pregnancy: a prospective study. Spine, 1996, 21: 702-709. [Medline] [CrossRef]

15) Ostgaard HC, Zetherström G, Roos-Hansson E: Back pain in relation to pregnancy: a 6-year follow-up. Spine, 1997, 22: 2945-2950. [Medline] [CrossRef]

16) Mogren IM, Pohjanen AI: Low back pain and pelvic pain during pregnancy: prevalence and risk factors. Spine, 2005, 30: 983-991. [Medline] [CrossRef]

17) Gutke A, Ostgaard HC, Oberg B: Pelvic girdle pain and lumbar pain in pregnancy: a cohort study of the consequences in terms of health and functioning. Spine, 2006, 31: E149-E155. [Medline] [CrossRef]

18) Gutke A, Josefsson A, Oberg B: Pelvic girdle pain and lumbar pain in relation to postpartum depressive symptoms. Spine, 2007, 32: 1430-1436. [Medline] [CrossRef]

19) Foti T, Davids JR, Bagley A: A biomechanical analysis of gait during pregnancy. J Bone Joint Surg Am, 2000, 82: 625-632. [Medline]

20) $\mathrm{Wu} \mathrm{W}$, Meijer OG, Lamoth $\mathrm{CJ}$, et al.: Gait coordination in pregnancy: transverse pelvic and thoracic rotations and their relative phase. Clin Biomech (Bristol, Avon), 2004, 19: 480-488. [Medline] [CrossRef]

21) Bird AR, Menz HB, Hyde CC: The effect of pregnancy on footprint parameters. A prospective investigation. J Am Podiatr Med Assoc, 1999, 89: 405-409. [Medline] [CrossRef]

22) Lymbery JK, Gilleard W: The stance phase of walking during late pregnancy: temporospatial and ground reaction force variables. J Am Podiatr Med Assoc, 2005, 95: 247-253. [Medline] [CrossRef]

23) McCrory JL, Chambers AJ, Daftary A, et al.: Dynamic postural stability in pregnant fallers and non-fallers. BJOG, 2010, 117: 954-962. [Medline] [CrossRef]

24) Dumas GA, Reid JG, Wolfe LA, et al.: Exercise, posture, and back pain during pregnancy. Clin Biomech (Bristol, Avon), 1995, 10: 104-109. [Medline] [CrossRef]

25) Curet MJ, Schermer CR, Demarest GB, et al.: Predictors of outcome in trauma during pregnancy: identification of patients who can be monitored for less than 6 hours. J Trauma, 2000, 49: 18-24, discussion 24-25. [Medline] [CrossRef]

26) Croteau A, Marcoux S, Brisson C: Work activity in pregnancy, preventive measures, and the risk of preterm delivery. Am J Epidemiol, 2007, 166: 951-965. [Medline] [CrossRef]

27) Kim HS, Yun DH, Yoo SD, et al.: Balance control and knee osteoarthritis severity. Ann Rehabil Med, 2011, 35: 701-709. [Medline] [CrossRef]

28) Calguneri M, Bird HA, Wright V: Changes in joint laxity occurring during pregnancy. Ann Rheum Dis, 1982, 41: 126-128. [Medline] [CrossRef]

29) Marnach ML, Ramin KD, Ramsey PS, et al.: Characterization of the relationship between joint laxity and maternal hormones in pregnancy. Obstet Gynecol, 2003, 101: 331-335. [Medline] [CrossRef]

30) Takeda K: A kinesiological analysis of the stand-to-sit during the third trimester. J Phys Ther Sci, 2012, 24: 621-624. [CrossRef]

31) Sihvonen T, Huttunen M, Makkonen M, et al.: Functional changes in back muscle activity correlate with pain intensity and prediction of low back pain during pregnancy. Arch Phys Med Rehabil, 1998, 79: 1210-1212. [Medline] [CrossRef]

32) Gilleard W, Crosbie J, Smith R: Effect of pregnancy on trunk range of motion when sitting and standing. Acta Obstet Gynecol Scand, 2002, 81: 1011-1020. [Medline] [CrossRef]

33) Levangie PK, Norkin CC: Joint structure and function: a comprehensive analysis. FA Davis, 2011.

34) Neumann DA: Kinesiology of the musculoskeletal system: foundations for rehabilitation. Elsevier Health Sciences, 2013.

35) Nakao H, Yoshikawa T, Mimura T, et al.: Influence of lower-extremity muscle force, muscle mass and asymmetry in knee extension force on gait ability in community-dwelling elderly somen. J Phys Ther Sci, 2006, 1: 18. [CrossRef]

36) $\mathrm{Wu} \mathrm{WH}$, Meijer OG, Bruijn SM, et al.: Gait in pregnancy-related pelvic girdle pain: amplitudes, timing, and coordination of horizontal trunk rotations. Eur Spine J, 2008, 17: 1160-1169. [Medline] [CrossRef]

37) Byrne NM, Groves AM, McIntyre HD, et al. BAMBINO group: Changes in resting and walking energy expenditure and walking speed during pregnancy in obese women. Am J Clin Nutr, 2011, 94: 819-830. [Medline] [CrossRef]

38) Gilleard WL: Trunk motion and gait characteristics of pregnant women when walking: report of a longitudinal study with a control group. BMC Pregnancy Childbirth, 2013, 13: 71. [Medline] [CrossRef] 